\title{
Characterizing the Seabed: a Geoscience Perspective
}

\author{
Alvar Braathen and Harald Brekke
}

The sea with its seabed has assets that have become extensively exploited as a source for food, energy and transport. Traditionally, the advancements of mankind on land have been more successful than in the oceans, mostly due to a physical setting that challenges easy-access and low-cost operations. However, this is gradually changing under the combined factors of the depletion of the required new resources as assets on land, and an increasing demand, resulting in an increased attention for the oceans. Meanwhile, the oceans remain mostly unknown, could be hostile and are for sure fragile.

In this contribution, our aim is not to explore the possibilities laying in the oceans and its seabed as other chapters in this book extensively cover them. Our objective is to inform about the seabed itself and define it, by asking some key questions that geoscientists could answer: What is the seabed made up of? Is the seabed a static entity or will the bed change over time? How could human activity influence the physical consistency of the seabed? These questions are basic but compulsory if one wish to implement a regulatory regime to seabed activities. It may be obvious, but decision-makers have to know what they regulate.

\section{What Characterizes the Seabed?}

The term seabed refers to the top-surface of earth in seas and oceans, also known as the seafloor or ocean floor. This surface has a topography, which is directly related to the nature of its subsurface geology, in places modified by ocean currents and sedimentary processes. Both the topography and the subsurface are important factors in the use of the seabed by humankind. From a resource perspective, humankind determines how resources from the seabed may be exploited and its resources distributed or protected by preventing 
exploitation. In all circumstances, the nature and accessibility of the seabed will be a crucial preliminary consideration. To understand the characteristics of the topography and subsurface of the seabed, we will have to look at the formation of the seabed, including the outer parts of the Earth's crust below oceanic water (2.1), and then the nature and processes of the interface between solid or semi-solid earth materials and water column in the sea (2.2). These are subjects covered extensively in many textbooks. ${ }^{1}$ Our approach is therefore that of a summary.

\subsection{The Earth's Crust}

The main geological difference between the continents and the deep oceans is the nature of the Earth's crust. In geology, one speaks of continental crust as opposed to oceanic crust. The continental crust is very thick $(20-40 \mathrm{~km})$ and relatively light, while oceanic crust is thin $\left(5^{-15} \mathrm{~km}\right)$ and considerably denser, as shown in figures 1 and 2 . This is because continental crust consists of light minerals rich in silica and aluminium, while oceanic crust consists of heavy, dense minerals rich in iron and magnesium. The effect of this is that the continents float high on the earth's mantle, like a cork on water, while the deep ocean floor is barely afloat, like a piece of heavy wood. This marked difference in buoyancy, thickness and relative elevation, is actually the underlying reason for the general global distribution of land and water. The thick buoyant continents support the vast areas of emergent land, while the heavy and low-lying oceanic crust forms the floor of the deep parts of the huge ocean basins that accommodate the world's seawater.

The differences between the continental and oceanic crust relates to the processes by which they are formed. The outer part of the Earth, including the crust, is divided into several large segments called lithospheric plates, which fit together like pieces in a jig saw puzzle. These plates 'float' and drift slowly in different directions upon the deeper mantle of the Earth. This implies that along some boundaries the plates separate and move away from each other (divergent boundaries), while along other boundaries they collide (convergent boundaries). In geology, this process is called plate tectonics.

Along the boundaries where plates separate, space is continuously created as the plates move away from each other at the speed of $1-10 \mathrm{~cm} / \mathrm{yr}$. This space is immediately filled by molten rock from the mantle in the form of intrusions and lavas, which solidify and form new crust. This is the way the dense and heavy oceanic crust is formed. The process is called ocean spreading since it

1 See notably: J.P. Kennett, Marine Geology (Prentice Hall, 1982); E. Seibold and W. Berger, The sea floor: an introduction to marine geology (Springer, 2017). 
implies that the ocean crust on both sides of the plate boundary is growing, causing the ocean to widen. Such widening oceans have all originated in breakup zones along which old continents were rifted apart by forces in Earth's mantle. These break-up zones then become new divergent plate boundaries between which the new ocean will form by ocean spreading. The Atlantic Ocean of today is such a spreading ocean, which accommodates increasing separation between the American continent on one side and Europe and Africa on the other.

Ocean spreading along some plate boundaries implies that other boundaries experience plate collision, making up convergent plate boundaries. At such boundaries, the crust of one plate will be forced under the other plate, with the contact termed a subduction zone. The heavy oceanic crust tends to be forced down. As the down-pressed plate moves down into the mantle in the subduction zone, the oceanic crust will melt again, and the molten rock will rise to the surface where it forms chains of volcanoes on the overriding plate. These volcanoes in many places form chains of islands, so called island arcs. Where the overriding plate is that of a continent the volcanoes becomes part of the margin of that continent. Water and sediments will be involved in the melting process within the subduction zone giving rocks enriched in light minerals akin to continental crust. As millions of years pass, such islands and/ or continental margins at convergent boundaries of plates will collide with islands or continents on other plates. Since they are formed of light rocks they will not be subducted into the mantle again, but tend to become accreted to the colliding islands or continent forming mountain chains. That is the way continents grow. For instance, the Pacific Ocean of today is surrounded by subduction zones where its oceanic crust disappears beneath the American and Asian continents. Millions of years into the future, the Pacific Ocean will close and the two continents collide.

Thus, the plate tectonic process results in a cycle where oceans come and go while continents collide and grow (Fig. 1.1 in Annex). The plate tectonic process started more than 4 billion years ago when the Earth had cooled sufficiently for molten rock to solidify and begin forming crust on the planet's surface.

\subsection{Seabed Topography}

The general topography of the seabed of the Earth may be described in terms of the continental shelf, the continental slope, the continental rise, the continental margin, and the deep ocean floor (Fig. 1.1). These terms are used partly in a legal sense by Article 76 of the United Nations Convention of the Law of the Sea (UNCLOS) to define the outer limits of coastal state's jurisdiction over the continental shelf. 


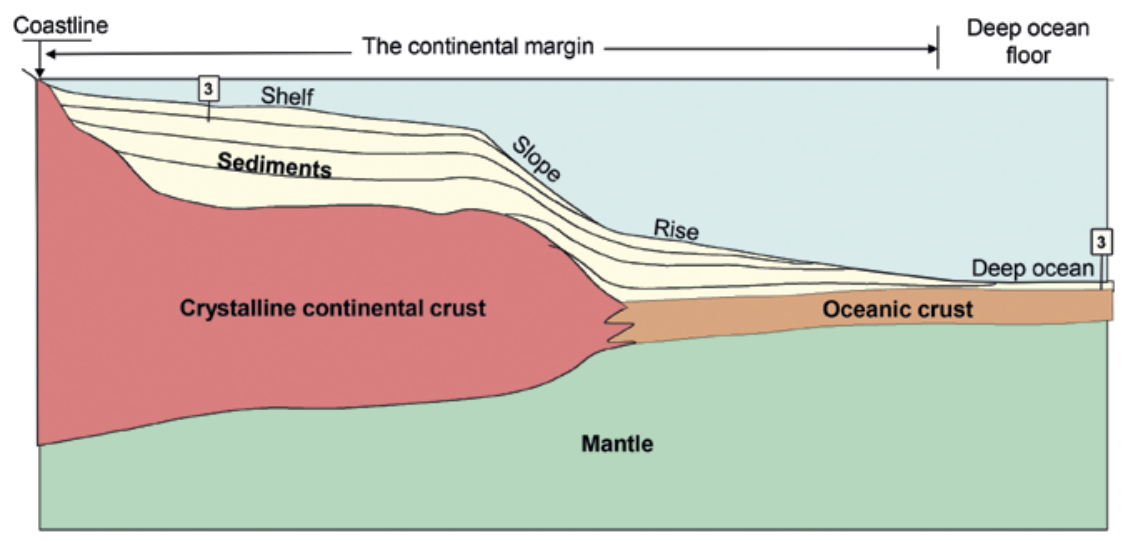

FIGURE 1.1 Profile showing a cross section of the elements of the general topography of the seabed extending from the coastline to the deep ocean floor

The topography of the seabed is related to the lateral distribution of the two types of crust, as shown in Figure 1.2. All the continents, which make up nearly all of the earth's land areas, have a continental shelf underlain by continental crust dominated by light components (minerals such as quartz and feldspar). This shelf is the part of the continent that is submerged below the sea, and make up vast areas of sea floor at a water depth starting at the beach and descending to some hundred meters. The shelf is bound seaward by the continental slope of similar light composition, dipping gently towards the deep ocean. In general, the continental slope is formed near the edge of the continental mass where the continental crust thins considerably and merges with the oceanic crust. At the base of the slope, at water depths below 3,000-4,000 meters, we reach the realm of the deep ocean floor that is underlain by oceanic crust made up of dark, heavy components. In many parts of the world one also finds a continental rise, which is an area of very gentle dip between the base of the slope and the deep ocean floor. The classical continental rise is a wedge shaped pile of sediments derived from the shelf areas and accumulated next to the base of the slope - in many places the sedimentary wedge partly overly oceanic crust.

In geology, the underwater areas of the planet are subdivided into two parts: the continental margins and the deep ocean floor. The continental margin extends from the shoreline to the end of the continental rise or to the base of the continental slope where no rise exists. The area seaward of the continental margin is the deep ocean floor.

The continental shelf is relatively flat and shallow. The widest continental shelves are found in the continental margins that were formed at divergent plate margins; also termed passive margins (see Fig. 1.1). Passive margins form 


\section{The Ocean Cycle}

\section{Opening and contraction}

1

2

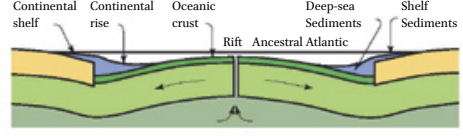

3

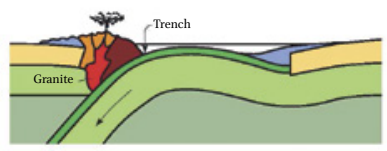

\section{Collision and re-opening}

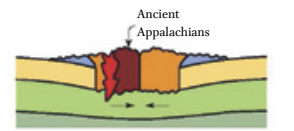

FIGURE 1.2 The Ocean Cycle. Schematic illustration of six progressive steps in the ocean cycle exemplified by the geological evolution of the Atlantic margins.

BASED ON PRESS AND SIEVER, 1974

1) The evolution starts with break-up, splitting North America from Africa, leading to formation of passive continental margins separated by oceanic crust gradually formed by intrusion of molten rock and extrusion of lavas at the midoceanic ridge (steps 1-2). This rifting and onset of ocean floor spreading of the Proto-Atlantic Ocean (the Iapetus Ocean) happened ca. 700 million years ago.

2) The mature stage of the ocean floor spreading in the Iapetus Ocean in Cambrian times (ca. 500 million years ago). In stages 1) and 2) the margins of the continents are tectonically and magmatically relatively passive while they are being progressively separated by the ocean floor spreading process. Continental margins in this geological setting are therefore termed 'passive margins'.

3) The contraction stage of the Iapetus Ocean in Ordovician times by the establishment of subduction zones along the continental margins. Such continental margins are tectonically and magmatically very active, and are therefore termed 'active margins'.

4) The collision between the old continents resulting in the final closure and destruction of the Iapetus Ocean and the consequent formation of the Appalachian/Caledonian Orogen (mountain chain) about 420 million years ago.

5) Renewed rifting along the axis of the orogen and re-establishment of seafloor spreading in the Atlantic Ocean through Jurassic and Cretaceous times. Note that continents at this stage have grown through the crustal material accreted at the continental margins during the continental collision and the previous ocean contractional stage.

6) Present spreading stage of the Atlantic Ocean where the passive continental marginsstill grow by the deposition of continentally derived sedimentsin the continental slopes along the outer parts of the margins.

Note: F. Press and R. Siever. Earth (W.H. Freeman and Company, San Francisco, 1974). 
by the extension and rifting of the continental crust prior to the break-up of the continent, ultimately leading to ocean floor and spreading. Thus, the widest continental shelves in the world are developed in the continental margins of the Atlantic Ocean. Narrow continental shelves are typical in continental margins associated with subduction zones at convergent plate boundaries: the active margins. They are generally narrow, as for instance seen along the western margin of the American continent.

All continental shelves end at the continental slope. The shape and nature of the continental slope vary considerably around the world. Along most passive continental margins, the continental slope forms an overall even surface with low gradients. Several of these slopes are underlain by large accumulations of sediment derived from rivers or glaciers that has draped and smoothed earlier topography. Such slopes are dominated by sedimentary processes and are generally accompanied by a large continental rise at the base of the slope. For other passive margins, however, the continental slope is a complex system of plateaus, ridges and steep escarpments formed by fault movements and from volcanic activity. For the active margins, the continental slope of the overriding plate typically constitutes the steep, landward slope towards the subduction trench (Fig. 1.2). Such trenches are the deepest places on Earth.

The topography of the deep ocean floor seaward of the continental slope is formed by the oceanic crust and later modified by sediment deposition. The oceanic crust is produced by volcanism (sea-floor spreading) along the diverging plate boundary. Hot rock is less dense than cold rock. Therefore, the young crust along the ocean spreading boundaries is relatively elevated to about 2,500 meters depth because the rocks are heated by the volcanic processes. Away from the spreading axis, the crust becomes denser as it cools with time and gradually subsides to large depths of about 4,000-6,00o meters. Thus, the spreading boundaries stand up as a global system of broad mountain chains (volcanoes) of the deep oceans. These mountain chains are called midocean ridges. The floor of these mid-ocean ridges is very irregular reflecting the original volcanic terrain of hills and mountains. Away from the elevated parts of the mid-ocean ridges, the crust becomes covered by sediment through time. In the deepest, older parts of the oceans the rugged terrain of the crust is totally buried by sediments, which forms the vast, flat abyssal plains of the world's oceans.

The oceans are locally punctuated by a different type of volcanic edifices, seen as seamounts that rise several thousand meters from the deep ocean floor. These volcanoes are geologically different from those of the ocean spreading process as they form above so-called hot-spots in the deep mantle. Many of these seamounts are surmounted by islands like those of Hawaii and Polynesia. 


\section{$3 \quad$ Seabed Composition and Its Mapping}

\subsection{Seabed Composition}

Earth materials in the surface seabed of the continental shelf is made up of a veneer of material falling out of suspension, such as dust from continents, biological material, sometimes ash and, more recently, human waste. Seafloor biological activity creates debris, for instance from reefs. Sand and mud is mostly supplied by rivers entering the ocean at given points. From their entry point, biological debris, sand and mud are washed around by waves and currents in the sea before settling in positions where wave and current action have limited impact. Typically, this process of deposition will create distinct layering, or stacking of beds, of which the younging-up order, or sequence, of distinct beds make up a lithostratigraphy (Fig. 1.3).

With increased burial by progressive burial, or chemical reactions between grains in sediments and fluids, initially unconsolidated biological debris, sand, mud and clay will start to advance mechanical strength by creating bonds in a process termed diagenesis. This is the path towards lithification that ultimately leads to rocks, such as limestone, sandstone, mudstone and shale underlying the unconsolidated to poorly consolidated upper beds underneath the seafloor.

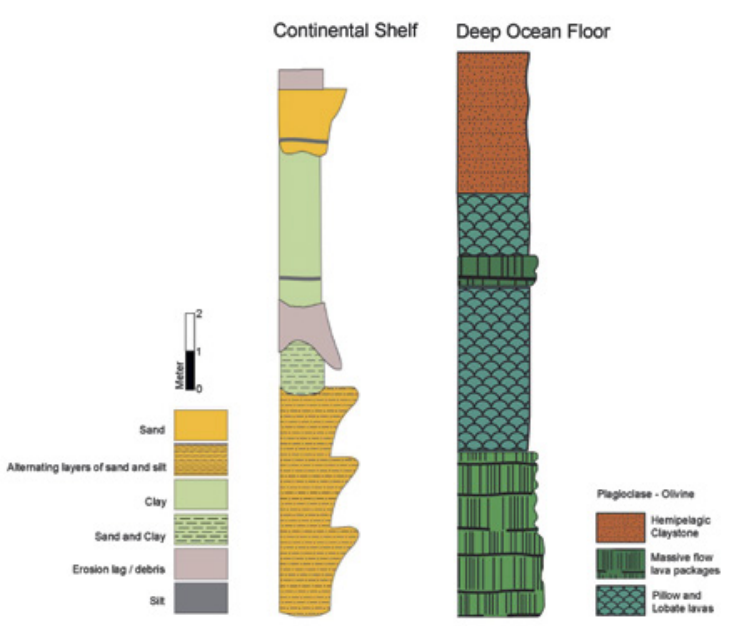

FIGURE 1.3 Typical lithostratigraphy of the continental shelf compared to similar stratigraphy of the deep ocean floor, shown in stratigraphic columns in which the total thickness would be between 10 and 100 meters in vertical section down from the sea-floor (on the top). The distribution of sediments such as sand and clay is directly linked to the source for various sediments and subsequently the physical conditions (waves, currents, composition) of the water column and its impact on the seafloor. 
The seabed of the deep ocean floor shows similar traits to beds of the continental shelf. However, with increasing distance to land (source of sand), limited seafloor biological activity, and depths excluding wave impact, a significant part of the seabed material has been falling out of suspension (ash, windblown dust, biological material). Local patches of sand and mud relates to infrequent currents down the continental slope. With the volcanic activity at the mid oceanic ridges, hard rocks from volcanic flows of the oceanic crust make up the units below the topside veneer of poorly consolidated sediments. Furthermore, cooling of volcanic material triggers hydrothermal activity, with seafloor groundwater venting revealed as black smokers.

\subsection{Mapping the Seabed and Its Composition}

In many parts of the world, the seafloor has been subject to mapping. For large areas, fairly detailed seafloor morphology maps are available, based in campaigns by national authorities, military activity, and compilation of datasets from mostly commercial ships equipped with advanced echo-sounders. The motivation for this work has been multifold, spanning form protection of reefs to placement of infrastructure. In Figure 1.4 we present one example, based on the Norwegian Mapping authority's (Kartverket ${ }^{2}$ ) efforts to manage the seafloor of the Barents shelf and nearby fjords of North Norway. ${ }^{3}$

In the case of the Barents Shelf seafloor, the mapping campaigns show that it is composed of sand, mud and shale, with some areas of concentrated biological activity displaying deep-water patch reefs. This distribution of materials on the seafloor is controlled by former or contemporaneous wave and current energy at the base of the marine water column. The basic physics behind moving sand or clay grains dictate that sand reflect most energy and shale lower energy. Noticeable, the energy level in areas with sand could be sufficient to create net seafloor erosion, hence causing gradual removal of the topmost part of the seabed.

In ford areas like in Norway, the sediment distribution is closer linked to land, as rivers convey the bulk of the sediments to the fjord basin. Accordingly, sand is found at the mouth of rivers and streams, whereas mud and clay settle from suspension further out in the fjord. As discharge by river can be very high and even episodic during floods, seabed thickness varies greatly from thick deltas to thin deep fjord deposits.

2 Norwegian Mapping Authority (Kartverket): <https://www.kartverket.no/>.

3 For further insight, information is given on the Geological Survey of Norway's website at $<$ www.ngu.no $>$. 


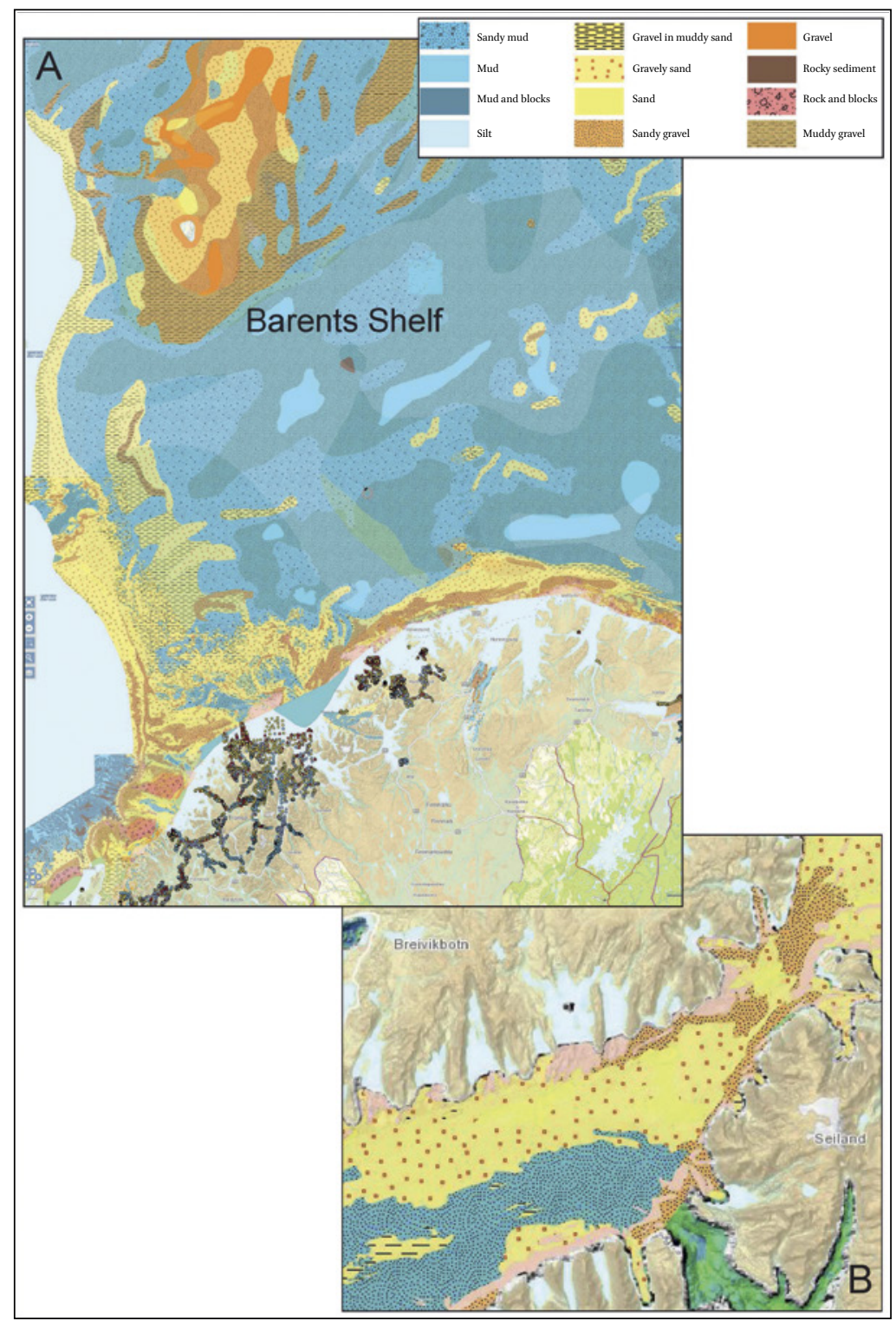

FIGURE 1.4 (A) Seafloor composition of the Barents Sea continental shelf, and (B) a similar map showing the seafloor composition in a fjord of North Norway.

EXAMPLES FROM THE DATABASE OF THE GEOLOGICAL SURVEY OF NORWAY (NGU) (WW.NGU.NO). WITH THE CONSENT OF NGU. 
Maps like those presented in Figure 1.4, directly describing seafloor composition, allow insight to temporal stability. The derived information is crucial for placement of infrastructure, as further outlined below. Such detailed data are nonetheless not common on a global scale. They mostly exist in ocean basins where there are significant national economic or other interests at stake. Hence, some areas of the world are already well mapped, while others are far from being mapped.

\section{$4 \quad$ Natural Processes in and on the Seabed}

As mentioned, in most places the seafloor experiences net deposition or erosion of sediments, although major or catastrophic events (e.g., storms, tsunamis, landslides) can temporarily change this status. From the moment a bed is building up, biological activity will modify its consistence. Most common is bioturbation by sediment eating organisms, consuming whatever organic material that has been captured in the sediment. These forms of life thrive in given positions, with deeper areas below the photogenic zone less attractive. Further, in shallow waters with extensive wave action, or in locations exposed to fresh water from streams, living conditions are uninviting. In areas where organic material is not fully consumed, there will be bacterial degradation creating gas (hydrocarbons). This gas is biogenic, and should not be mistaken as thermogenic gas. The latter relates to chemical reactions in organic shales (and sometimes limestones) that survived the biological activity and experienced deeper burial. As described above, deeper burial instigate the transition to rock that, combined with general heating, mobilize hydrocarbons in organic beds. Byproducts are gas and oil.

The transition from loose sediment to rock linked to compaction from burial and chemical reactions reduces the pore space available for fluids. Fluids will typically be captured sea water or groundwater that migrate in from other beds. General compaction reduces available space for fluids, forcing them to migrate. As basically all fluids are lighter than rock and earth materials, this migration follows paths that eventually will bring fluids to the surface, unless trapped. The consequence is that large parts of the seafloor experience expulsion of fluids such as fresh or salt (brine) ground water, biogenic and thermogenic gas and even oil. Much of this relaxed flow is bypassing the seabed during migration from deeper geological units to the surface.

There are numerous examples of the fluid expulsion at the Earth's surface, with two illustrations presented in Figures 1.5 and 1.6. This phenomenon is not unique to the oceans, and excellent natural examples of it can be found 


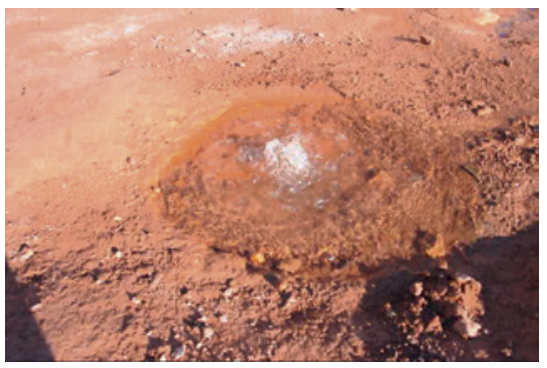

FIGURE 1.5

$\mathrm{A} \mathrm{CO}_{2}$ leak in Utah, USA

PHOTOGRAPH BY ALVAR BRAATHEN

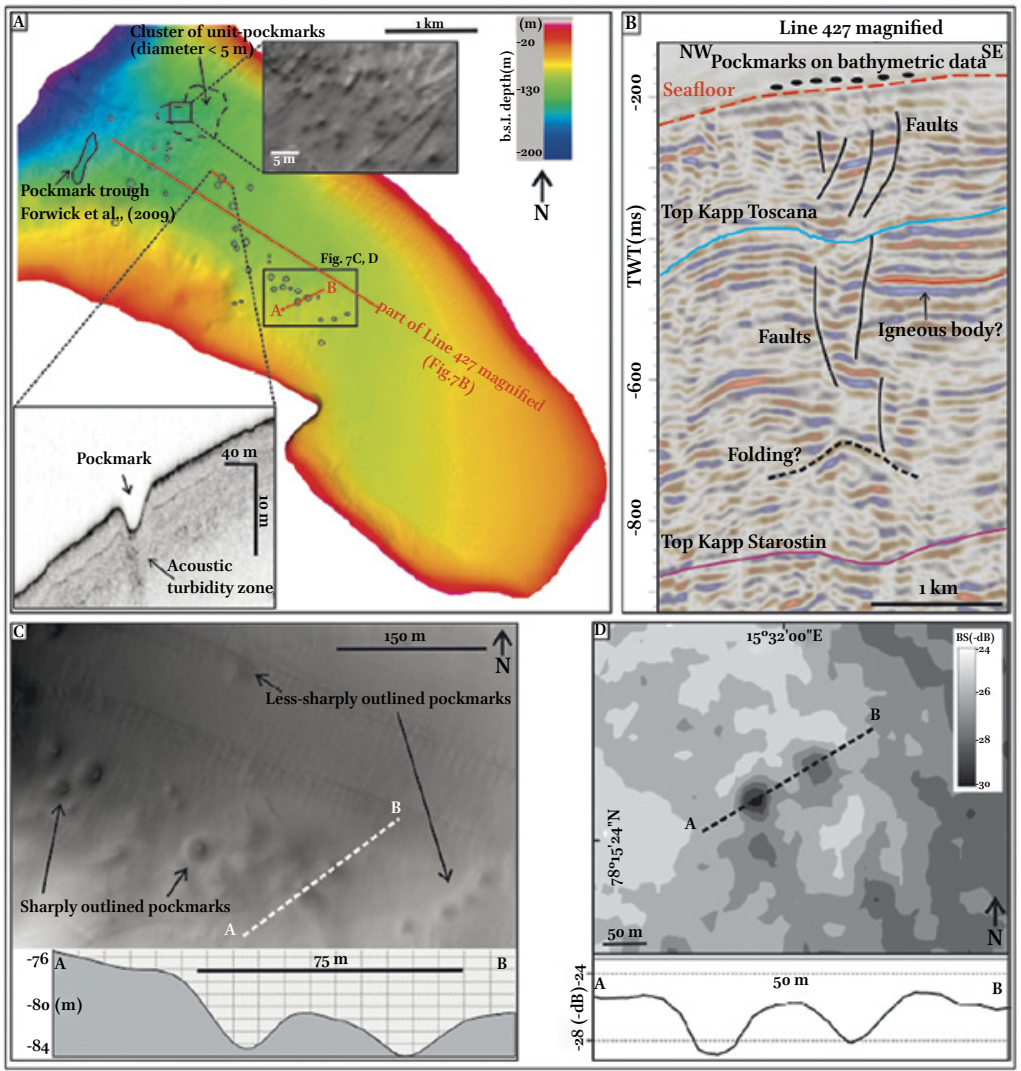

FIGURE 1.6 Pockmarks of Isfjorden, Svalbard, Norway. High-resolution multibeam bathymetric data from $\mathrm{SAl}$ (Adventforden) showing the distribution of pockmarks. (A) The dashed-line area has c. 25-30 unit-pockmarks (top inset: magnified unit-pockmarks on bathymetric data; bottom inset: acoustic turbidity zone beneath a pockmark on the sub-bottom profile. (B) Structural interpretation of 2 D seismic data (Line 427) in deeper successions beneath the pockmarks. (C) Sharply and less-sharply outlined circular pockmarks. Profile A-B across the pockmarks is illustrated beneath. (D) Multibeam backscatter data and corresponding A-B profile across the pockmarks in Fig. C.

MODIFIED FROM ROY ET AL. 2016 
onshore, such as in Utah (Southwest USA). This region display numerous sites that leakage natural $\mathrm{CO}_{2}$ to the Earth's surface from deeper reservoirs/aquifers. Extensive geological investigations suggest fluids migrate up conduits along narrow zones in the crust that have experienced earthquakes and which are called faults. This migration has lasted for at least 400,000 years. ${ }^{4}$ Not surprisingly, drilling in 1937 next to a $\mathrm{CO}_{2}$ charged spring punctured one fluid migration route, triggering significant $\mathrm{CO}_{2}$ outbursts.

Another example of fluid expulsion from the seafloor can be found in the pristine High Arctic of Norway (see Figure 1.6). In Svalbard, the Longyearbyen $\mathrm{CO}_{2}$ Lab project undertook mapping of the fjord seafloor as a baseline study. The concept was to map pre-existing leaks before starting injection campaigns into rocks nearby. Investigations found hundreds of small depressions with circular rims on the seafloor, so-called pockmarks. ${ }^{5}$ They are formed by fluids or gas rising out of the seabed, lifting away sediments and gradually forming a 1-10 m deep crater. Mobilized sediments settle along the rim of the crater. As the wilderness of Svalbard has experienced minimal impact by human activity, this illustrates how fluid migration to the seafloor is a natural process, with pockmarks as the physical evidence. For the $\mathrm{CO}_{2} \mathrm{Lab}$, key questions were attached to timing of fluid migration and flow rate. A central question was notably to know whether these pockmarks were the result of ongoing flow. Most pockmarks turned out to be dormant, reflecting former fluid expulsion episodes. However, a few pockmarks in the fjord are active, showing mainly methane gas mixed with ground, where thermogenic gas is sourced from the deep subsurface. The organic black shales of the Svalbard bedrock emit natural gas.

For the broader audience, the two examples of Utah and Svalbard discussed above offer a higher learning value, which is that, basically, all geological materials will leak, given sufficient time. However, these leaks are overall slow and will seldom be catastrophic (in geology terms this means shorter than thousand years).

4 B. Dockrill, and Z. Shipton, 'Structural controls on leakage from natural $\mathrm{CO}_{2}$-geologic storage site: Central Utah', U.S.A., Journal of Structural Geology, v. 32, no. 11 (2010) 1768-1782.

5 S. Roy, M. Hovland, \& A. Braathen, 'Evidence of fluid seepage in Grønfjorden, Spitsbergen: Implications from an integrated acoustic study of seafloor morphology, marine sediments and tectonics,' Marine Geology, no. 380 (2016), 67-78. 
The resources of the seabed are both geological and biological. Geological resources are found on the surface - mainly as sand and gravel, and deep sea minerals -, as well as in the subsurface of the seabed - mainly as oil and gas. Biological resources in the form of sedentary organisms live on or just below the surface as part of the biodiversity, with species specialized according to available resources, depending on the composition of the surface and subsurface of the seabed, and the associated geological processes.

The floor of the continental shelf is usually underlain by thick sequences of sediments that may host hydrocarbon resources. This is especially the case for continental shelves of passive continental margins where the sediments may date back to long before the break-up of the continent. Therefore, these margins host most of the offshore oil and gas industry of the world.

Continental shelfs worldwide is the site for anchored infrastructures, for instance drill holes that bypass the seabed on their way to the deeper subsurface and which are placed there to extract hydrocarbons. Other drill holes are used to inject (waste-)water, gas or, in a few places, even anthropogenic $\mathrm{CO}_{2}$. Decades with learning around these operations make them familiar to the general public, although technical challenges around infrastructure placement such as wells are resolved by experts. Similar knowledge exists around harvesting of biota from the seafloor (algae, shell fish, etc.) and, to a lesser extent, mining biota in the uppermost seabed for instance by seafloor trawling. These undertakings are well regulated in most waters, with national and bilateral agreements regulating undertakings. ${ }^{6}$

The deep ocean floor at 1000's of meters depth has been regarded economically less interesting as it is nearly barren of life that can be harvested. However, a growing global population facing the transition to a society increasingly dependent on digital processes and renewable energy has given rise to a general agreement that there will be an increasing demand for metals in the future, both in volume and diversity. This notion is reflected in the current significantly growing interest in deep sea mining. Exploration for deep sea polymetallic minerals is taking place both in the continental shelf areas of coastal states and in the international seabed (the Area). At present, there are 29 exploration contracts in the Area, and the activity is expected to move

6 See R. Caddell, Chapter 12 of this book, 'Deep-Sea Bottom Fisheries and the Protection of Seabed Ecosystems: Problems, Progress and Prospects.' 
to exploitation in a near or not too far future. ${ }^{7}$ There are two main types of polymetallic deposits on the seafloor of the deep oceans: ferro-manganese minerals and seafloor massive sulphides. ${ }^{8}$ The ferro-manganese mineral deposits are formed by oxyhydroxide minerals of iron and manganese, which also carry minor, but economically interesting quantities of nickel, copper, cobolt, rare earth elements (REE) and other metals. They form two types of deposits: nodules and crusts. The individual nodules are formed as concentric layers of minerals that are precipitated from the seawater above the seafloor or from the pore water of the sediments just below the seafloor. Nodules grow in areas of very sparse sedimentation and form large nodule fields in the abyssal plains that lie far from the sediment sources of the continents. The largest nodules fields are found in the Pacific Ocean. The ferro-manganese crusts grow as mineral lamina precipitated onto surfaces of bare rock on the seafloor (e.g. escarpments, ridges and seamounts). Such crusts are found in all oceans.

The seafloor massive sulphides are formed by hydrothermal processes associated with volcanic activity, mainly along the mid-ocean ridges of the oceans (see above Section 2.2). The heat of the volcanic activity sets up a circulation system of hot water within the ocean crust, leaching metallic elements from the rock and carrying them up to the seafloor in hydrothermal vents. In contact with the cold seawater, the metals will precipitate as a black cloud of sulphides; hence the name 'black smokers'. Such deposits are known from all oceans, and some of them are already the object of industry activity. The Canadian company Nautilus is currently developing a sulphide deposit called 'Solwara' within the Exclusive Economic Zone (EEZ) of Papua New Guinea. ${ }^{9}$ The Japanese agency JogmeC in August 2017 carried out a successful test of mining equipment on a sulphide deposit in the Okinawa Trough. ${ }^{10}$ It seems that deep sea mining will take place as affordable technology opens new avenues.

How will human activity on the seabed impact the local environment? Infrastructure on the shelf such as oil platforms are anchored by traditional

7 See website of the International Seabed Authority at <https://www.isa.org.jm/>. For an analysis of the applicable legal regime, see J. Dingwall, Chapter 7 of this book, 'Commercial Mining Activities in the Deep Seabed Beyond National Jurisdiction: The International Legal Framework.'

8 See R. Sharma (ed.), Deep-Sea Mining. Resources Potential, Technical and Environmental Considerations, (Springer International Publishing, 2017).

9 See further information on the website of the company Nautilus Minerals Inc at $<$ http:// www.nautilusminerals.com/IRM/content/default.aspx>.

10 'Japan successfully undertakes large-scale deep-sea mineral extraction,' Japan Times, 26 September 2017 <https://www.japantimes.co.jp/news/2017/og/26/national/japan -successfully-undertakes-large-scale-deep-sea-mineral-extraction/\#.XA19JGyWyhc>. 
methods (chain and anchor) or, for some installations, stands on the seafloor by their own weight. Others stand on pillars knocked into the seabed. Future production facilities will however to a larger degree lay on the sea floor or be dug into the seabed. Common for all these semi-permanent facilities is that they cause changes in the physical conditions for the seafloor, thereby impacting the seabed with time. Waves amplify when hitting obstacles such as pillars, drill hole casings, storage tanks or tubes/cables, increasing the likelihood for erosion of the seafloor. On the contrary, infrastructure dampening the sea could cause deposition. Infrastructure also has a load that could cause subsidence. Further, infrastructure could generate heat and/or light impacting the biological environment. All these effects are in most cases technically manageable if considered when it comes to design. Similarly, environmental impacts caused by local sea floor modifications, or even spills, have been extensively analyzed, as has the ownership and obligations to acreage. The environmental impacts from local seafloor modifications are also regarded a major issue to be considered with regard to the future deep sea mining for minerals; or similar mining for biota in the seabed of the shelfs.

\section{Geoscience Posts to the Regulatory Community}

Our considerations around the seabed, based on our background as geologists, bring forward many aspects that are well known, and well regulated, but we feel that a reminder is in any case valuable. In order to reach science-based decisions reflecting a precautionary approach, lawmakers must get access to sufficient insight to understand the implications and impacts that the envisaged new laws may cause. 